\title{
Can Digital Technologies Speed up Real Estate Transactions?
}

\author{
Andrew Baum ${ }^{\mathrm{a}}$, Andrew Saull ${ }^{\mathrm{a}}$, Fabian Braesemann*a \\ ${ }^{a}$ Saïd Business School - University of Oxford \\ *fabian.braesemann@sbs.ox.ac.uk, ORCID-ID: 0000-0002-7671-1920
}

\begin{abstract}
Purpose. This study presents a structured investigation of the most important causes for delay in commercial real estate transactions. It assesses the potential of digital technologies such as 'Blockchain', 'Property Passports' or 'Automated Valuation Models' to make transactions faster and cheaper.

Methodology. We conduct a focus group interview to identify the individual steps and the parties involved in real estate transactions. Subsequently, we discuss the prospects of digital technologies based on semi-structured interviews with real estate professionals and PropTech executives, and a comprehensive screening of technological solutions offered by PropTech firms.

Findings. The lack of a an up-to-date, single pool of standardised property information turns out to be the most critical cause for delay in real estate transactions. However, the most promising technologies to mitigate this problem, in particular digital property passports summarising all relevant building information, face substantial barriers to adoption. The real estate industry has so far not been willing to more openly share data, which is a pre-requiste for the successful introduction of property passports. In addition, the principle of caveat emptor makes a lengthy due diligence process essential for buyers.

Implications. We conclude that industry-wide collaborations are necessary to help major efficiency gaining technologies to break through. Insurance products should accompany property data log books to guarantee the quality of data provided.

Originality. This study considers the potential impact of technologies in the wider context of the complete real estate transaction process. It identifies the major phases of that process and the associated bottlenecks. We gather evidence both from industry experts and PropTech executives and contrasts their views regarding the potential of digital technologies to remove those bottlenecks.
\end{abstract}

JEL classification: K 25, L 85, O 33, R 33

Keywords: Commercial Real Estate - Real Estate Transactions • PropTech • Property Passport • Blockchain • Automated Valuation Models

\section{Introduction}

Land shelters us, feeds us, and provides us with space for recreation, shopping, and work. With total global real assets valued at more than $\$ 238$ trillion (Savills, 2017), land as an investment is a significant component of the global economy. At the same time, transacting real estate is a costly and time-intensive process. For example, the registration of a property in the United Kingdom (UK) takes, on average, 22 days, and costs up to $5 \%$ of the total property value (WorldBank, 2018).

In this paper, we investigate the most important causes for delay in commercial real estate transactions in the UK, and we discuss how digital technologies could make this process faster and cheaper.

For this purpose, we conduct a focus group interview with commercial real estate experts, who were asked to construct a process map of the steps required for a hypothetical transaction. More than 150 individual steps and seven major causes for delay were identified. In the second step, we assessed the potential of digital technologies to overcome these blockages, based on desk research and interviews with executives from established real estate firms and PropTech start-up firms. 
In summary, we could identify a lack of an up-to-date single pool of standardised property information to be the most critical cause for delay. However, technological solutions to effectively provide such information require many complementary investments and legal adjustments, which impedes their introduction. In contrast, more specialised technologies focusing on individual inefficiencies in the conveyance process face less entry barriers and are, hence, more likely to be adopted.

In the following section, we briefly describe the current conveyancing and registration process in the United Kingdom, before we present the identified causes for delay in 3. Section 4 discusses the potential of digital technologies to reduce these blockages and barriers to adoption. Section 5 concludes.

\section{Conveyancing and registration processes}

A commercial land transaction broadly consists of five steps involving a host of actors. Sellers and their agents are responsible for (1) the preparation and (2) marketing required to establish an asking price of a property. Solicitors then organise the conveyance - the administrative process by which rights over land are transferred. This step includes all necessary legal works during (3) the due diligence period and (4) the post-exchange period. Finally, a land registry collects taxes and records the legal ownership during the post-completion period.

The success of a property transfer can be measured by how closely the conveyancing process conforms to initial expectations, most importantly determined by the time it takes until settlement occurs. In practice, conveyancing processes in the current paper-based system are often delayed, as transaction times run beyond expectations. In the UK, for example, delays occurred in close to $40 \%$ of all transactions (NewStatesman, 2018).

Improvements in the UK registration system have, so far, been hampered by a lack of digitalised (in other words, machine-readable) data: while the vast majority of service requests to Her Majesty's Land Registry (HMLR) are placed in a digitised format (HMLR, 2017), many of these requests are lodged as scanned PDF documents (digital copies of the original document). These scanned records still rely on manual interpretation to extract relevant information. The efficiency gains of using such digitised documents are, thus, limited.

While many PropTech companies (Shaw, 2018) currently offer digitalised platforms which could contribute to more streamlined property transaction processes, many of them are siloed solutions for specialised problems, which do not take problems of software and data integration into account. As a consequence, the real estate industry is slow at adopting these new technologies.

In order to make real estate transactions more efficient and to ease the conveyancing burden for firms and individuals, it was suggested that a single system connecting all the agencies that supply information involved in property transfers needs to be established (Abbey et al., 2017, p. 41). Such a single portal system is generally known as 'e-conveyancing'.

However, e-conveyancing has so far not been successful in the United Kingdom. HMLR's pilot project Chain Matrix failed, as it suffered from poor software integration, and non-digital procedures slowing down the transaction chain. Similarly, VEYO, an e-conveyancing attempt from the Law Society has not been adopted widely (Solomons, 2016). In contrast, Australia's PEXA system provides a functioning e-conveyancing platform, after being mandated by the Australian government (Deloitte, 2018).

\section{Causes for delay in the current transaction process}

Data are fundamental at every stage in a property's lifecycle: when buying an asset, investors need information about building operations, cash flows, maintenance and capital expenses, potential risks, market assumptions, tenancy schedules and more. These data need to be transferred efficiently from 
and to previous and current owners, legal advisors, property managers and others, but this process is commonly subject to inefficiency and delays.

To reveal the information processing steps necessary for a real estate transaction, and to identify the bottlenecks in information transfer, we organised a focus group interview with real estate experts from HMLR, two major UK law firms and a leading real estate advisory firm in August 2018. We asked the participants to construct a process map outlining the individual steps required for a hypothetical transaction. The experts identified 150 individual steps and seven major blockages to efficient commercial transactions that take place in the five phases of a typical real estate transaction.

Details on the process mapping exercise are provided in the supplementary materials (section S1). The process maps itself can be found in the online supplement. ${ }^{1}$

\section{The preparation period}

The transaction process begins with the vendor's decision to sell. Here, the vendor assembles relevant data about the property in consultation with a lawyer, real estate advisor, or property manager and instructs a broker or selling agent to prepare marketing materials.

Cause for delay 1: the vendor may not have accurate or digital records of relevant information. This problem arises when the selling agent attempts to collect relevant, accurate, up to date information about the property in order to set a realistic asking price. Data about the property are often not readily available, outdated, might be lost, or held in different formats across several organisations.

With many vendors having information stored in paper format, or composed of scanned documents, data extraction can become a tedious, time-intensive, and unsatisfactory process. This process is error-prone, as critical dates or changing lease clauses might easily be overlooked.

\section{The marketing period}

During the marketing stage, the vendor's solicitors make data available to potential buyers through the data room, a single portal connecting all parties involved in a transaction. Additionally, the buyers may visit the property, carry out surveys, use drones, GPS or virtual reality to collect more information about the object.

Cause for delay 2: inconsistent approaches to data rooms. Often, different software packages are used to compile relevant information for a potential transaction, bearing the risk of incompatible formats. The lacking integration between the software used to produce spreadsheets and tables with that used for creating detailed legal information packs is compounded by individual firms having their own systems for logging extracted information and uploading documents for file sharing.

The lack of standardised format within data rooms leads to disorganised taxonomies of content provided by third parties. This makes locating any relevant uploaded information a difficult process. Moreover, differing software systems at individual firms may block downloading files whose names do not meet the requirements of their cyber-security firewalls. This is particularly pertinent in cases where the seller's solicitor does not have the capabilities to host a data room and instead uses a generic file sharing platform.

\section{The due diligence period}

During this period, the buyer's legal team runs searches of utility providers, local authorities and others who may hold information relevant to the value of the property.

\footnotetext{
${ }^{1}$ https://github.com/Braesemann/RETransactions
} 
Cause for delay 3: performing adequate searches via under-resourced authorities and utilities companies. The search process may create substantial delays, due to inefficiencies and under-investment in record-keeping, cutbacks in funding of local authorities, or a lack of motivation where the search fee does not cover the work involved.

While every property deal requires a set of standard searches, more complicated transactions require additional information. Third party organisations, most importantly the local government's land charge departments, hold a wide range of the relevant data. Depending on the operational structure of these departments, the relevant information might be held in a manner of mixed formats. Thus, necessary search information needs to be individually requested from each department in order to achieve an appropriate degree of due diligence.

Cause for potential delay 4: identifying the correct parcel. Because HM Land Registry is not digitalised, there might be inconsistencies between (a) the paper plans and digitised maps held by HMLR, (b) the plans given to conveyancers, (c) the parcels identified during site visits, and (d) the boundaries provided by geolocation or satellite imaging technology.

This is aggrevated by HM Land Registry's use of the general boundaries rule (HMLR, 2003). Historical registry techniques identified these boundaries using a pencil outline drawn upon a low-resolution map. Subsequent manual copying of these historical maps along with digitised copies and subsequent transference between online data rooms has created the potential for varied interpretations of the same 'truthful' boundary.

Cause for potential delay 5: completing standard enquiry forms. Commercial Property Standard Enquiry Forms or CPSEs were introduced in 2002 to reduce bottlenecks during the due diligence period (LawSociety, 2002). Their rationale is that if known information about any potential risk involved in the transaction of the property were disclosed by the seller prior to exchange of contracts, this would speed up the due diligence process on the buyer's side by avoiding any late re-negotiations.

However, CPSEs have caused further unwanted bottlenecks: although sellers have a duty of care, some lack the motivation to provide information relating to deficiencies that potentially reduce their negotiating power. Instead, many enquiries on CPSEs are completed with terms to the effect of 'the buyer should rely upon its own searches and enquiries' (caveat emptor).

Cause for potential delay 6: reviewing and reporting using non-integrated software. In reporting to the client, the buyer's solicitor will consolidate all necessary information into one document including planning advice, rights of and burdens on the title and key information on the occupational leases. Extracting the relevant information for this report, again, throws up the issue of data formats.

The siloed operations of each party has led to the growth of software packages focused on specific aspects of a transaction, showing little consideration for other data requirements. Moreover, many tasks rely on platforms that were not designed with a real estate specific purpose.

The most up to date lease information extraction technologies use machine learning systems to identify relevant terms and clauses from contracts to create digitalised, machine readable copies (e.g. EVANA or Open Box). However, these systems are yet unable to deal effectively with complexity, as they do not register with similar technologies on the agency side of the transaction.

\section{The post-exchange period}

During the post exchange period, the parties have time to comply with any conditions that are to be dealt with before completion can take place (such as third party consent to the transaction). They 
will also tidy up administrative details and accounting records, agree completion apportionments, and prepare transfers.

\section{The post-completion period}

After completion, Stamp Duty Land Tax is required to be paid. The title is then registered at HMLR, generally submitted electronically by the purchaser's solicitor.

Cause for delay 7: lack of transparency over requisitions and delays in registration. When a transfer of ownership takes place, it is legally required that the new property ownership is registered through HMLR. This process is processed through the online portal or business gateway provided by the Land Registry. To ensure the validity of any transfer of title, HMLR must first run checks on the information provided and consult their database for any prior unresolved issues, which may prevent them from legally registering a new owner. Where title registration cannot be validated and therefore processed, a query ('requisition') is raised of the buyer's solicitor.

While such requisitions are generally easily resolved, substantive responses to an application are often delayed, and solicitors express a lack of practical guidance to prepare applications appropriately. Further causes for delay arise when third parties refuse to give consent for the evidence required to clear titles of historic charges and encumbrances (Robertson, 2017).

An important implication of the delay between completion and registration is that the new owner is not able to raise debt or finance the object during this period, as the new owner not yet holds official rights over the property. As this delay is very common, many contracts include clauses for the seller to act on behalf of the buyer while the requisitions are dealt with.

\section{Analysis}

Most causes for delay represent data storage and transfer issues. However, available digital technologies in commercial conveyancing have mostly focused on digitising current workflows. While this offers a more efficient transfer of information than paper-based processes, it lacks the capability of automating the full spectrum of tasks required for efficient real estate transactions. Moreover, the principle of caveat emptor (Johnson, 1985), i. e. the principle that the buyer is responsible for checking the quality of goods before a purchase is made, makes a lengthy due diligence process essential for buyers. This contributes to long transaction processes.

All participants in the mapping process agreed that an openly accessible, single pool of standardised, up to date property information could reduce most of the causes for delay highlighted. Such property passports or data log books could be traded along with the title of a property. They could, thus, form a foundation upon which layers of digital software can be iteratively laid to more efficiently transfer and process transaction related information.

\section{Applicable technologies and barriers to adoption}

Having analysed the causes for delay in commercial real estate transactions, it is clear that removing these bottlenecks would speed up property transactions. Here, we explore the potential of individual technologies to reduce some of these delays. For this assessment, we draw on desk research and a screening of PropTech firms to identify technologies and solutions. Additionally, we identify the operational, regulatory and social barriers which need to be overcome before adoption, based on semi-structured interviews with real estate professionals and PropTech executives we have conducted from September to December 2018.

Details on the interviews, including question guides and interview-notes are provided in the supplementary materials (sections S2, S3, and S4). Section S5 lists start-ups working on relevant technologies. 


\subsection{Applicable technologies}

Several technologies might be applicable in the broader transaction process. These include automated valuation models (Schulz et al., 2014; Cajias, 2019; Alexander-Dietzel et al., 2014), satellites and drones for property inspection (Law et al., 2018; Marhani, 2018), lease information extraction software using machine learning techniques (Burdick et al., 2014), and virtual and augmented reality software as alternatives to on site visits (Farshid et al., 2018). These technologies help to collect and process relevant information about properties and might, hence, speed up the transaction process. Technologies that more closely focus on real estate conveyancing are blockchain-based transactions (smart contracts), property passports, and blockchain land registries. We will briefly introduce these technologies and their potential to reduce causes for delay in the following.

\section{Blockchain transactions: smart contracts}

A serious inefficiency under the present conveyancing process is that all parties involved in a real estate transaction 'have to validate the data which they receive. All these validations result in higher transaction costs in the brokerage, legal, recording, and banker fees' (Deloitte, 2017, p. 6).

Blockchain - a distributed database containing immutable data items - has the potential to transform ownership records and transaction processes for every conceivable asset type (Veuger, 2018; Hoxha and Sadiku, 2019). It might be the basis for smart contracts, which could have a substantial impact on real estate transactions (Qiu et al., 2019; Wouda and Opdenakker, 2019). For example, a smart contract could simultaneously transfer funds from buyer to seller while registering the buyer as the new real estate title holder once all contracts are digitally signed, exchanged and validated. They could, in particular, help an improved information maintenance and exchange of information between the involved parties. Such contracts have already been piloted successfully by start-ups in residential real estate.

For example, ChromaWay, an early-stage venture from Sweden, has developed a private Blockchainbased transaction system to eliminate the need for individual data verification. The Silicon Valley based firm Propy follows the existing structure of a real estate transaction while it records each phase in a parallel Blockchain process. This necessary iteration helps to gain trust in the underlying system, but the current duplication of processes eliminates much of the potential efficiency gains of the new technology.

Moreover, registries have so far been reluctant to legally recognise Blockchain-produced ownership titles. This has created serious blockages to the progress of Blockchain-based transactions.

In summary, Blockchain-based smart contract transactions are unlikely to become a reality in the near future as this would require the development, use and interaction of Blockchain-based systems for all parties in a transaction including registries, banks, buyers and sellers.

\section{Property passports}

The idea of a property passport is simple: to store all the information relating to an individual property in its own unique digital data file. This file is to be maintained by the owner or tenant of the property and transferred along with the title (Sesana and Salvalai, 2018).

While iterative steps towards a property passport can be made using state-of-the-art technologies, a comprehensive, transparent, and cost-efficient property passport will require the integration of digital technologies, in particular interconnected sensor technologies ('Internet of Things', 'Building Information Modelling') and automatised tools to manage tenants and properties (Fields, 2019; Ganter and Lützkendorf, 2019). In theory, such updated digital log books have the potential to provide the standardised pool of information that the real estate experts identified as the most important step to remove many of the delays in property transactions.

However, in the absence of regulatory change, the impact of property passports will be restrained by reservations against data sharing innovations and risk aversion. In particular, a potential buyer will 
only rely on information provided in a property passport, if the seller can guarantee the accuracy of that information. If it is erroneous, inaccurate risk assessments and subsequent losses might occur, so that the buyer will have a recourse against the seller.

\section{Blockchain land registration}

Blockchain can, moreover, be applied to land registration (Lazuashvili et al., 2019; Keilitz and Wiipongwii, 2017). If Blockchain land recording is further developed, the real estate market could become more transparent as the availability and quality of real estate data will increase (Swan, 2017; Lemieux, 2016). The need for title insurance will be reduced, as proof of ownership can be established indelibly on the blockchain (Spielman, 2016).

While Blockchain technology offers many benefits to the land registration process, procedural elements still need to be addressed. Graglia and Mellon (2018), for example, highlight seven pre-requisites for a successful introduction of Blockchain land registry. ${ }^{2}$ Accordingly, recent Blockchain-based land registry pilots in the United States and Brazil have encountered problems: they lacked a critical mass of adopters, local authority representatives opposed the project as they worried to be replaced by automated systems, and they faced high implementation costs.

\section{Analysis}

The applicability of different technologies to the identified causes of delay are summarised in table 1 . This assessment is based on the interviews with real estate professionals (details in supplementary materials). It should be noted that the table below focuses on the applicability of a technology to reduce a cause for delay in principle. It does not assess whether a certain cause will be fully resolved.

Blockchain-based smart contracts, property passports and Blockchain-based land registrations could potentially reduce many causes for delay, in particular in the critical due diligence period of a transaction. The other technologies rather focus on more specific inefficiencies. The property passport concept has the highest potential impact on the causes for delay.

\begin{tabular}{|c|c|c|c|c|c|c|c|}
\hline Causes for delay & $\begin{array}{c}\text { Smart } \\
\text { contracts }\end{array}$ & $\begin{array}{l}\text { Property } \\
\text { passports }\end{array}$ & $\begin{array}{l}\text { Blockchain } \\
\text { land registr. }\end{array}$ & $\begin{array}{c}\text { Satellites \& } \\
\text { drones }\end{array}$ & $\begin{array}{l}\text { Lease info. } \\
\text { extraction }\end{array}$ & AVMs & VR/AR \\
\hline (1) Information maintenance & $\checkmark$ & $\checkmark$ & $\checkmark$ & $\checkmark$ & $\checkmark$ & $\checkmark$ & $\checkmark$ \\
\hline (2) Data rooms & $\checkmark$ & $\checkmark$ & & & $\checkmark$ & & \\
\hline \multicolumn{8}{|l|}{ Due Diligence period } \\
\hline (3) Searches & $\checkmark$ & $\checkmark$ & & & & $\checkmark$ & \\
\hline (4) Parcel identification & & $\checkmark$ & $\checkmark$ & $\checkmark$ & & & \\
\hline (5) Standard enquiry forms & & $\checkmark$ & $\checkmark$ & & & $\checkmark$ & \\
\hline (6) Reporting & $\checkmark$ & $\checkmark$ & & & $\checkmark$ & & \\
\hline (7) Registration & & & $\checkmark$ & & & & \\
\hline
\end{tabular}

Tab. 1. Applicability of technologies to identified causes for delay in commercial real estate transaction processes

\subsection{Barriers to the adoption of technology}

While several technologies are being developed to reduce the time and cost of property transactions, their existence alone does not automatically lead to successful adoption. Regulation, innate conservatism, and a reluctance to commit to untried innovations all play their part in holding back change.

Together with the interviewed real estate and PropTech experts, we identified major barriers to adoption of digital technologies in the real estate transaction process. The barriers can be categorised as

\footnotetext{
${ }^{2}$ These are: an identity solution, digitalised records, multi-signature wallets, a private or hybrid Blockchain, accurate data, connectivity infrastructure and a technology aware population, and a trained professional community.
} 


\begin{tabular}{|c|c|}
\hline \multicolumn{2}{|l|}{ Operational barriers } \\
\hline Software integration & New systems must integrate with existing legacy practices and software. \\
\hline Standardised digital data & Technological efficiency relies on up to date, accurate digitalised data. \\
\hline Critical mass & Due to network effects, novel systems can only be successful if they are widely used. \\
\hline Transition costs & $\begin{array}{l}\text { Considerable financial investments are needed to replace existing software and hard- } \\
\text { ware and to up-skill labour force. }\end{array}$ \\
\hline Data security & $\begin{array}{l}\text { Easily accessible data are vulnerable to data breaches; it is vital to ensure that new } \\
\text { systems are resilient against cyber-attack. }\end{array}$ \\
\hline \multicolumn{2}{|l|}{ Regulatory barriers } \\
\hline Legal framework & $\begin{array}{l}\text { Novel systems must conform with existing legislation; some solutions, like Blockchain } \\
\text { land registrations, might require legal adjustments. }\end{array}$ \\
\hline Technology transparency & $\begin{array}{l}\text { Solutions must be transparent as to their data sources and the reasoning behind any } \\
\text { outputs. }\end{array}$ \\
\hline \multicolumn{2}{|l|}{$\underline{\text { Social barriers }}$} \\
\hline Expected benefits & $\begin{array}{l}\text { More efficient technologies should benefit their target users to bring incentives for } \\
\text { adoption. The long term financial benefits must be clearly understood. }\end{array}$ \\
\hline Disintermediation & $\begin{array}{l}\text { Some participants in current conveyancing systems might be replaced by digitally } \\
\text { mediated transactions. Novel solutions must clearly sketch these effects and align } \\
\text { incentives for potential adopters. }\end{array}$ \\
\hline Trust in innovation & $\begin{array}{l}\text { Unclear functionality, benefits, and associated risks of novel solutions can reduce trust } \\
\text { and hold back investment and private sector data collaborations. }\end{array}$ \\
\hline
\end{tabular}

Tab. 2. Potential barriers to technology adoption

operational, regulatory and social. Operational barriers identify the process changes and complimentary investments needed in either the legacy systems, the real estate industry, or the platforms developed by technology start-ups.

Regulatory barriers highlight the legal issues related to novel technologies, while social barriers relate to the more behavioural and emotional limits to the adoption of any new system of transacting property. Table 2 lists the most important perceived barriers to adoption of digital technologies in each category.

During the interviews, we have asked the participants to assess in how far the identified technologies have overcome the barriers to adoption. Table 3 provides a synopsis of this assessment.

From this analysis, those technologies that face the lowest barriers to adoption and are therefore most likely to impact the commercial transaction process in the near term are:

- Satellites and drones - allowing boundaries and property conditions to be inspected through a multitude of emerging imaging methods and location data.

- Lease information extraction software - using machine learning image recognition software to digitalise hard and soft copies of documentation required for the transaction process.

- Virtual and augmented reality - using image capture software to enable interactive, remote inspections and viewings.

While these technologies will help to streamline specific elements of real estate transactions, the technologies that could have a more profound impact on the efficiency of real estate transactions (Blockchainbased smart contracts, property passports, and Blockchain land registrations) are considered to be far from wide-scale adoption. The biggest barriers to adoption are the absence of standardised digital data, a perceived risk of disintermediation and operational problems of data security.

Extrapolating this analysis to cover the five periods of a typical commercial real estate transaction, we 
can infer that imminent technologies are most likely to shorten the preparation period and the marketing period in the near future. The due diligence phase, which causes most delays, is the hardest to disrupt.

\begin{tabular}{|c|c|c|c|c|c|c|c|}
\hline Barriers to adoption & $\begin{array}{c}\text { Smart } \\
\text { contracts }\end{array}$ & $\begin{array}{l}\text { Property } \\
\text { passports }\end{array}$ & $\begin{array}{l}\text { Blockchain } \\
\text { land registr. }\end{array}$ & $\begin{array}{c}\text { Satellites \& } \\
\text { drones }\end{array}$ & $\begin{array}{l}\text { Lease info. } \\
\text { extraction }\end{array}$ & AVMs & VR/AR \\
\hline Operational barriers & & $\checkmark$ & & $\checkmark$ & $\checkmark$ & $\checkmark$ & $\checkmark$ \\
\hline Software integration & & $\checkmark$ & & $\checkmark$ & $\checkmark$ & $\checkmark$ & $\checkmark$ \\
\hline Standardised digital data & & $\checkmark$ & & $\checkmark$ & $\checkmark$ & $\checkmark$ & $\checkmark$ \\
\hline Critical mass & & & & $\checkmark$ & $\checkmark$ & $\checkmark$ & $\checkmark$ \\
\hline Transition costs & & $\checkmark$ & & $\checkmark$ & $\checkmark$ & $\checkmark$ & $\checkmark$ \\
\hline Data Security & & & $\checkmark$ & $\checkmark$ & $\checkmark$ & $\checkmark$ & $\checkmark$ \\
\hline Regulatory barriers & & $\checkmark$ & $\checkmark$ & $\checkmark$ & $\checkmark$ & & $\checkmark$ \\
\hline Legal framework & & $\checkmark$ & & $\checkmark$ & $\checkmark$ & $\checkmark$ & $\checkmark$ \\
\hline Technology transparancy & $\checkmark$ & $\checkmark$ & $\checkmark$ & $\checkmark$ & $\checkmark$ & & $\checkmark$ \\
\hline Social barriers & & $\checkmark$ & & $\checkmark$ & $\checkmark$ & & $\checkmark$ \\
\hline Expected benefits & & $\checkmark$ & $\checkmark$ & $\checkmark$ & $\checkmark$ & & $\checkmark$ \\
\hline Disintermediation & & $\checkmark$ & & $\checkmark$ & $\checkmark$ & & $\checkmark$ \\
\hline Trust in innovation & & & & $\checkmark$ & $\checkmark$ & $\checkmark$ & $\checkmark$ \\
\hline
\end{tabular}

Tab. 3. The extent to which applicable technologies have overcome barriers to adoption (no: , somewhat: $\checkmark$, yes: $\checkmark$ )

\section{Discussion}

\subsection{Summary}

In this study, we identified the most important causes for delay in commercial real estate transactions and the potential of digital technologies to reduce them. For this purpose, we performed a focus group exercise with real estate experts, focusing on the case of a hypothetical transaction of a real property. The experts identified more than 150 interrelated steps involved in a typical commercial real estate transaction and seven major blockages in that process.

Based on the process mapping, we performed a qualitative screening of the PropTech industry to identify potential digital technologies that could help to make transactions more efficient. These technologies were then assessed via desk research and a second round of semi-structured interviews with real estate professionals and PropTech executives.

The following results emerge. The due diligence phase involves most causes for delay in the transaction process. The main reason for delays, over all phases in a typical real estate transaction, is the absence of a trusted, standardised, up-to-date, single pool of property information. The conveyancing process involves several redundancies and manual, potentially error-prone information collection and processing steps that could be substantially reduced, if the transacted property was accompanied by a trusted digital data file containing all relevant information.

Several technologies are developed to potentially reduce delays in real estate transactions. The most promising are Blockchain-based smart contracts, digital property passports, and Blockchain land registrations. However, operational, regulatory, and social barriers impede the adoption of these technologies. In particular, the real estate industry has, so far, not been willing to more openly share information and to make investments in such technologies. 
The benefits of these technologies can only be realised if they are widely adopted and accepted as standardised tools by all parties involved in transacting real estate. Thus, isolated solutions are not likely to be successful and PropTech start-up firms will lack the market power to make their innovative solutions the next industry standard. As a consequence, less radical technologies offering digitalised solutions for more specific elements of the transaction process - satellites \& drones and Virtual \& Augmented Reality applications for property inspection, as well as lease information extraction software - have been more successful in overcoming adoption barriers.

\subsection{Methodological limitations}

To discuss a real case in this study, we had to narrow the scope of the analysis and to make some assumptions. First, our analysis has focused on the conveyancing process in England and Wales. This was necessary to discuss a real case and to identify the numerous interactions and legal requirements that led to the more than 150 individual steps of a property transactions we identified in the focus group exercise. However, we believe that our results can be generalised to other countries, as most of the revealed inefficiencies are due to a lack of standardised digital data and a variety of involved parties, and not due to the UK-specific land registry system.

Secondly, we had to limit the number of potentially applicable technologies to be discussed in this study. The selection is based on our screening of the PropTech industry, numerous industry events and discussions with real estate professionals. While many more technological solutions are developed by innovative PropTech firms, those discussed here are perceived to have the most profound impact on transacting commercial property.

Thirdly, in this study we discuss the possible impact of technologies and potential barriers to their adoption. The majority of the technologies presented here are still under development and they have not yet been widely adopted. Thus, our results should be interpreted as probabilistic assessments given the current state of development. Moreover, our qualitative research methodology tried to capture the sentiment and perceived bottlenecks in the real estate industry. This method is not capable of producing quantitative predictions. Future research should, thus, take a more quantitative perspective and assess the degree to which real estate transactions could be made more efficient due to the discussed technologies.

\subsection{Conclusion}

Digital technologies have the potential to increase market transparency, improve liquidity and bring lower transaction costs. This could have a positive impact on the value of investment assets (Trofimov et al., 2016).

A fully digitalised Land Registry, for example, could connect all the agencies involved in an individual conveyance, enabling the frictionless access, transfer, automation and validation of required information. This would reduce the reliance on human processes and cut out many of the transaction bottlenecks caused by disparate sources of information. However, digital technologies have so far only been trialled, and full digitalisation is far away.

In theory, real estate transactions could be fully automated, they could be conducted peer-to-peer without intermediaries and cross borders, facilitated by the use of Blockchain conveyancing software. However, real estate transactions must comply with existing legislation and some of the more ambitious innovations would require unlikely changes in contract law.

An important step in making real estate transactions more efficient is the establishment of a single pool of up-to-date, standardised property information. An example of such standardised property information is the property passport, a digital file containing the legal and physical data relating to an individual property, held and transferred along with its title. 
Despite obvious benefits, risk aversion, the threat of disintermediation and lost revenues have so far impeded the adoption of such technologies and the sharing of data.

As a potential driver of adoption, insurances guaranteeing the veracity of the data stored in property passports might, therefore, be a suitable solution (Ganter and Lützkendorf, 2019). Such insurances would provide protection against false or missing information and could help to substantially shorten the due diligence phase, which is causing most delays. Lower insurance premiums could be offered to landlords in exchange for accurate information, enabling better predictions of risks associated with the property. Similarly, enhanced terms could be offered by lending organisations who have a vested interest in compiling as much accurate and up to date information about a property as possible.

While many start-up businesses currently work on property passport solutions, change can only be facilitated, if all groups involved in real estate conveyancing work together: government, private businesses, industry associations and the public. Any single group is unable to drive change alone.

The government will need to encourage the digitalisation of national and local authority records and to define clear regulations surrounding real estate data ownership. PropTech firms should not only focus on highly specialised solutions to improve specific aspects of transactions, but also consider the integration of their products in the wider transaction pipeline. Industry groups have to develop standards and protocols encouraging data sharing and record keeping, and the public will need to develop a much clearer sense of responsibility for collecting and storing data describing one of the most valuable asset classes, and a better sense of the value of these data.

In the pursuit of efficiency, it is important to ensure the systems by which real estate - the primary capital resource of any economy - is registered and conveyed are transparent, secure and quick (Lindqvist, 2012). Those economies best able to harness the economic and social benefits which come with a high quality of land administration and transference have simple fast-track procedures, low transfer taxes, fixed registration fees, digital registries and time limits for administrative procedures.

Start-ups working on highly specific process improvements coupled with data-sharing industry associations and groups, supported by motivated and educated government agencies will help to shorten the time taken to buy and sell real estate; but substantial improvements in real estate transaction processes can only occur if all these actors work together.

\section{References}

Abbey, R., Richards, M. B., Richards, M., 2017. A practical approach to conveyancing. Oxford University Press.

Alexander-Dietzel, M., Braun, N., Schäfers, W., 2014. Sentiment-based commercial real estate forecasting with Google search volume data. Journal of Property Investment \& Finance 32 (6), 540-569.

Burdick, D., Franklin, M., Issler, P., Krishnamurthy, R., Popa, L., Raschid, L., Stanton, R., Wallace, N., 2014. Data science challenges in real estate asset and capital markets. In: Proceedings of the international workshop on data science for macro-modeling. ACM, Snowbird, Utah, pp. 1-5.

Cajias, M., 2019. Understanding real estate investments through big data goggles: A granular approach on initial yields. International Journal of Housing Markets and Analysis 12 (4).

Deloitte, 2017. Blockchain and real estate: Mining unexplored terrain. Report, Deloite Netherlands.

URL https://www2.deloitte.com/content/dam/Deloitte/nl/Documents/real-estate/deloitte-nl-fsi-reblockchain-in-re.pdf

Deloitte, 2018. Impacts of e-Conveyancing on the conveyancing industry. Report, Deloitte Australia, Sydney.

URL https://www2. deloitte.com/content/dam/Deloitte/au/Documents/Economics/deloitte-au-economics-impacte-conveyance-pexa-220518.pdf

Farshid, M., Paschen, J., Eriksson, T., Kietzmann, J., 2018. Go boldly!: Explore augmented reality (AR), virtual reality (VR), and mixed reality (MR) for business. Business Horizons 61 (5), 657-663. 
Fields, D., 2019. Automated landlord: Digital technologies and post-crisis financial accumulation. Environment and Planning A: Economy and Space.

Ganter, M., Lützkendorf, T., 2019. Information management throughout the life cycle of buildings-Basics and new approaches such as blockchain. In: IOP Conference Series: Earth and Environmental Science. Vol. 323. IOP Publishing, p. 012110.

Graglia, J. M., Mellon, C., 2018. Blockchain and Property in 2018: At the End of the Beginning. Innovations: Technology, Governance, Globalization 12 (1-2), 90-116.

HMLR, Oct. 2003. HM Land Registry plans: boundaries (practice guide 40, supplement 3). Report PG40s4, HMLR, London.

URL https://www.gov.uk/government/publications/land-registry-plans-boundaries/land-registry-plansboundaries-practice-guide-40-supplement-3

HMLR, 2017. Business Strategy 2017-2022. Report, HMLR, London.

URL https://assets.publishing.service.gov.uk/government/uploads/system/uploads/attachment_data/file/ 662811/HM_Land_Registry_Business_strategy_2017_to_2022.pdf

Hoxha, V., Sadiku, S., 2019. Study of factors influencing the decision to adopt the blockchain technology in real estate transactions in Kosovo. Property Management 37 (5).

Johnson, H., 1985. 'Caveat Venditor'('Let the Seller Beware'). Managerial Law 27 (6), 1-19.

Keilitz, I., Wiipongwii, T., 2017. Blockchain and International Development: Can Blockchain Technology Be the Solution to Effective Land Registration Systems in Developing Nations. Wm. \& Mary Pol'y Rev. 9 (1), 52-72.

Law, S., Paige, B., Russell, C., 2018. Take a look around: using street view and satellite images to estimate house prices. arXiv preprint arXiv:1807.07155.

LawSociety, Oct. 2002. Commercial property standard enquiries. The Law Society Gazette.

URL https://www.lawgazette.co.uk/news/commercial-property-standard-enquiries/38188.article

Lazuashvili, N., Norta, A., Draheim, D., 2019. Integration of Blockchain Technology into a Land Registration System for Immutable Traceability: A Casestudy of Georgia. In: Lecture Notes in Business Information Processing. Vol. 361. Springer, Cham, pp. 219-233.

Lemieux, V. L., 2016. Trusting records: is Blockchain technology the answer? Records Management Journal 26 (2), $110-139$.

Lindqvist, S., 2012. The concept of transparency in the European Union's residential housing market: a theoretical framework. International Journal of Law in the Built Environment 4 (2), 99-115.

Marhani, A. R., 2018. The Utilization of Drones for Smart Governance Implementation: Tax Extensification Strategy for Transfer of Ownership in Real Estate Sales at Cibinong Primary Tax Office. In: International Conference on ICT for Smart Society (ICISS). IEEE, Semarang, Indonesia, pp. 1-6.

NewStatesman, Jun. 2018. The future of home-buying: How technology is set to transform conveyancing. The New Stateman. URL http://www.newstatesman.com/sites/default/files/future_of_home_buying_supp_clc_6th_april_2018.pdf

Qiu, L., Zhao, Y., Liu, Q., Sun, B., Wu, X., 2019. Intelligent transaction: definition, modes, and research directions. International Journal of Crowd Science 3 (1), 36-48.

Robertson, A., Dec. 2017. Quality Time. Property in Practice.

Savills, 2017. Global Real Estate: Trends in the world's largest asset class. Report, Savills World Research, London. URL https://www.savills.co.uk/blog/article/216300/residential-property/how-much-is-the-world-worth . aspx

Schulz, R., Wersing, M., Werwatz, A., 2014. Automated valuation modelling: a specification exercise. Journal of Property Research 31 (2), 131-153.

Sesana, M. M., Salvalai, G., 2018. A review on Building Renovation Passport: Potentialities and barriers on current initiatives. Energy and Buildings 173, 195-205.

Shaw, J., 2018. Platform Real Estate: theory and practice of new urban real estate markets. Urban Geography, 1-28.

Solomons, P., Jan. 2016. Paperless Conveyancing: the Rise and Fall of Veyo.

URL https://www.solomonslaw.co.uk/paperless-conveyancing/ 
Spielman, A., 2016. Blockchain: digitally rebuilding the real estate industry. PhD Thesis, Massachusetts Institute of Technology.

URL http://hdl.handle.net/1721.1/106753

Swan, M., 2017. Anticipating the economic benefits of blockchain. Technology Innovation Management Review 7 (10), $6-13$.

Trofimov, S., Szumilo, N., Wiegelmann, T., 2016. Optimal database design for the storage of financial information relating to real estate investments. Journal of Property Investment \& Finance 34 (5), 535-546.

Veuger, J., 2018. Trust in a viable real estate economy with disruption and blockchain. Facilities 36 (1/2), 103-120.

WorldBank, 2018. Doing Business 2018: Reforming to Create Jobs. Report, World Bank. URL https://www.doingbusiness.org/en/data/exploretopics/registering-property

Wouda, H. P., Opdenakker, R., 2019. Blockchain technology in commercial real estate transactions. Journal of Property Investment \& Finance 37 (6), 570-579. 


\title{
Can Digital Technologies speed up Real Estate Transactions?
}

\author{
- Supplementary Materials - \\ Andrew Baum ${ }^{\mathrm{a}}$, Andrew Saull ${ }^{\mathrm{a}}$, Fabian Braesemann*a \\ ${ }^{a}$ Sä̈d Business School - University of Oxford \\ *fabian.braesemann@sbs.ox.ac.uk, ORCID-ID: 0000-0002-7671-1920
}

\section{Contents}

1 Focus group process mapping $\quad 1$

2 Interview data generation $\quad 4$

2.1 Sampling process . . . . . . . . . . . . . . . . . . . . . . 4

2.2 Interview guide . . . . . . . . . . . . . . . . . . . . . . 4

2.3 Data . . . . . . . . . . . . . . . . . . . . . . . . . 6

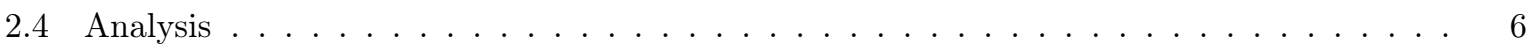

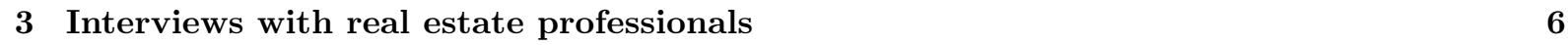

3.1 Innovation Strategist $(\mathrm{M})$, large London based real estate firm . . . . . . . . . . . . 6

3.2 Digital Director $(\mathrm{M})$ and IT Director $(\mathrm{M})$, large London landlord . . . . . . . . . . . . . 8

3.3 Council $(\mathrm{F})$, large London legal practice . . . . . . . . . . . . . . . . . . . . . . 9

3.4 CEO (M), Real Estate Innovation Consultancy . . . . . . . . . . . . . . . . . . . . . . 10

3.5 Vice President (M) and Head of Automation (M), intelligence / news firm . . . . . . . . . 12

4 Interviews with PropTech executives 13

4.1 CEO (M) and Software Engineer (F), Blockchain-based Property Passports . . . . . . . . 13

4.2 CEO (M), Automated Valuation Model . . . . . . . . . . . . . . . . . . . . 14

4.3 CEO (F), Online Property Passports . . . . . . . . . . . . . . . . . . . . . 16

4.4 CEO (M), Auto Valuation Model . . . . . . . . . . . . . . . . . . . . . . 17

4.5 Head of Corporate Development (F) and Chief Software Engineer (M), Smart Contracts . 18

5 List of Start-ups working on specific technologies $r$

$\begin{array}{lr}\text { References } & 22\end{array}$

\section{Focus group process mapping}

Data collection utilised a focus group comprising of 14 representatives from five leading firms within the UK commercial conveyancing industry. The group were moderated by three researchers from Saïd Business School, University of Oxford. This explorative qualitative method was selected due to a lack of insight into the transaction process within the literature and an absence of available quantitative data through which to obtain any significant findings. The use of focus groups enables researchers to determine the extent to which there are shared views among a group of people in relation to a specific topic (Denscombe, 2010:177).

The brief to participants was to map all individual actions required for the hypothetical, end to end transaction of a commercial office building (see figure S1).

Images of the case study building: 
- 6 St Giles Court, Reading, UK, RG1 2QL,

- Acquired on December 2000 for $£ 112,500$,

- Agreed purchase price of $£ 180,000$.
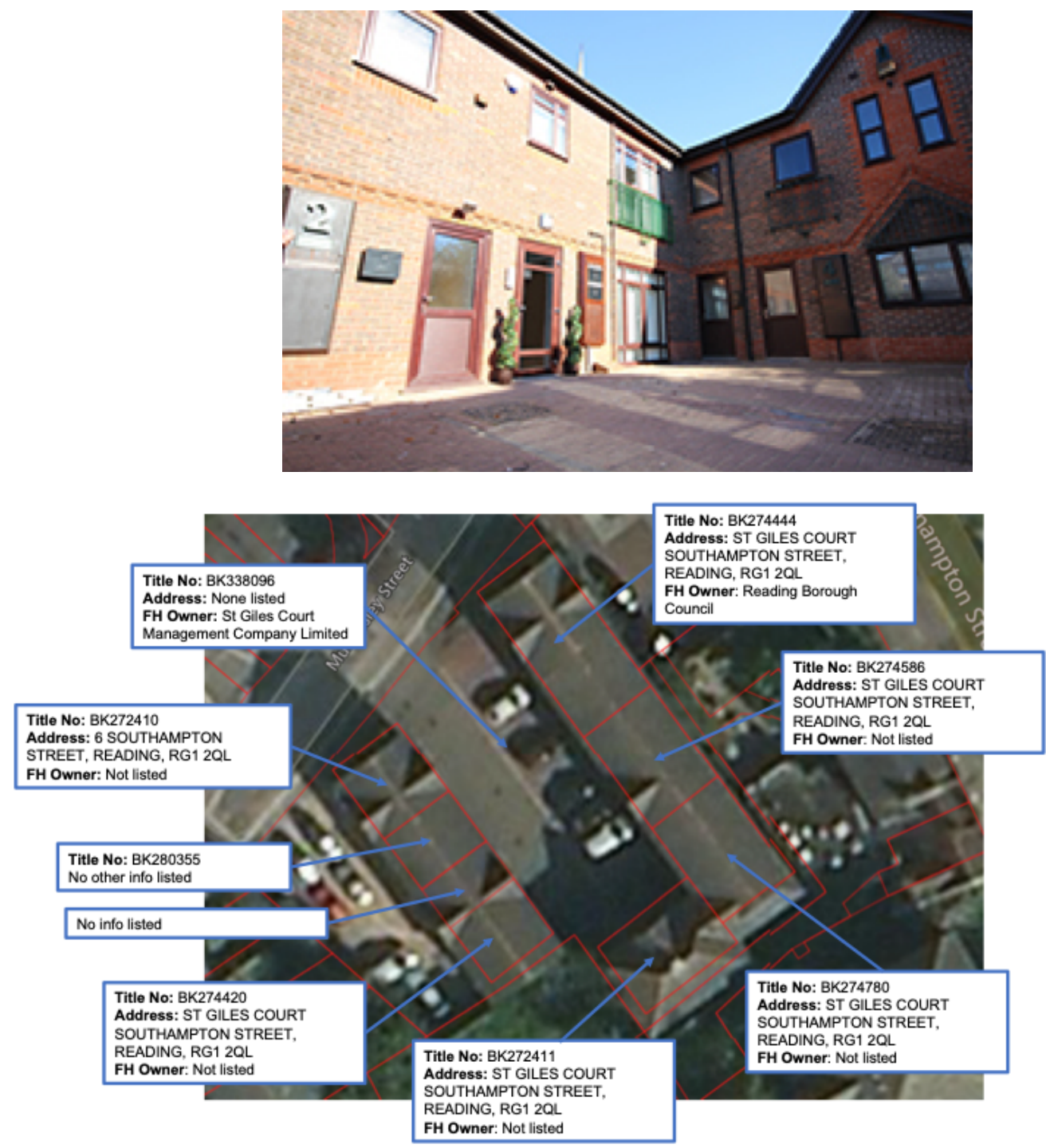

Fig. S1. The property to be transacted (upper panel) and the plot of land to be transacted (lower panel)

It was decided, due mainly to time constraints, that the hypothetical purchase would involve $100 \%$ equity as any introduction of debt would further obfuscate an already complex process and the necessary publishable findings would not result. While the building is real, its sale was hypothetical to avoid any conflicts of interest or legal liability.

\section{Participants}

Each participating firm adopted the role of an instructed actor involved in a typical transaction. Where requested, details of the participating firms have been anonymised, along with all employee identities. ${ }^{1}$ Their assumed roles are included in the following table. Due to an under-representation of Agents in the

\footnotetext{
${ }^{1}$ Instead, we provide generic names.
} 
sample, Mr Andrews from a Property Management Firm assumed the role of both the vendor's and the buyer's agent.

\begin{tabular}{|c|c|c|}
\hline Role & Firm(s) & Participant(s) \\
\hline Owner / Vendor & Pension Scheme A & Researcher A \\
\hline \multirow[t]{2}{*}{ Acting for Vendor } & London Law Firm A & $\begin{array}{l}\text { Mrs Smith } \\
\text { Mrs Stone } \\
\text { Mr Samuel } \\
\text { Miss Samson } \\
\text { M Mr Saunders }\end{array}$ \\
\hline & Property Manager & Mr Andrews \\
\hline Buyer & Developer A & Researcher B \\
\hline \multirow[t]{2}{*}{ Acting for Buyer } & Solicitor & $\begin{array}{l}\text { Mrs Jones } \\
\text { Mrs Jenkins } \\
\text { Mr Johnson }\end{array}$ \\
\hline & Property Manager & Mr Andrews \\
\hline Occupier & Research Company A & Researcher C \\
\hline Local Search Provider & Search Acumen & Mr Walker \\
\hline Land Registry & HMLR & $\begin{array}{l}\text { Mr Whiter } \\
\text { Miss Red } \\
\text { Mr Brown }\end{array}$ \\
\hline
\end{tabular}

Tab. S1. Roles in the process mapping exercise

Each necessary action to be undertaken during the commercial conveyance was mapped onto a chronological timeline, while simultaneous questions were raised and potential causes for delay were discussed.

Data to be analysed took three separate formats, collected by the three researchers. This enabled for a process of triangulation during later analysis (Denscombe, 2010: 346), revealing common themes and identifying the main causes for delay in the transition process.

The first format is a visual process map, simultaneously produced as data collection progressed. A process map was chosen as the best way of identifying the multi-linear processes which occur during a real estate transaction. Different colour post-it notes were used to denote either an action, a feeling or a suggested cause for delay. These were placed in the chronological order in which events unfold.

The second format are manuscripts of all conversations taking place while the process map was being constructed, handwritten by the three researchers involved in the focus group exercise. These notes enabled any individual sentiment to be captured and correctly attributed. With the aim of the focus group to primarily identify cost and time inefficiencies, this method of recording emotion was an accurate way to convey the level of frustration felt towards any given cause for delay, not always reserved for those demanding the greatest cost or time.

The final data collected during this focus group mapping activity was held in a spreadsheet, detailing the technical issues discussed around the identified causes for delay, such as historical causes, previous attempts to fix the system and perceived reasons for their existence. This was done to inform additional study, where the researcher may have been unaware or hold a low understanding of certain specific actions.

Informal follow up interviews with individual participants were held at a later date to cross check the validity of data while enabling an opportunity to expand upon points made and adding further clarity. These interviews offered a chance for individuals to reveal any points which may have been uncomfortable to raise in front of a wider group. The resulting process maps from the focus group exercise can be found 
in the online supplement. ${ }^{2}$

\section{Interview data generation}

\subsection{Sampling process}

Technology adoption does not follow simplified mathematical diffusion models. Instead, as Straub (2009: 627) suggests, there is no single adoption-diffusion model that provides sufficient explanation towards actual technology use.

While adoption-diffusion models may be limited by their lack of complexity, one common theme in the organisational technology adoption literature concerning successful technology diffusion is the presence of an internal 'innovation champion'. Hoffman (2011: 48) points towards research which identifies these champions as either powerful individuals in an organization or lower-level individuals with the ability to influence the actions of others. These characteristics are reinforced by Levison and Levison (2019: 3): "Experience has shown us that for a new technology to be successfully adopted there needs to be an internal champion. That champion can be a member of the executive leadership team or someone held in high regard within the organization". More empirically, Vagnani and Volpe (2017) find strong evidence that the behavioural preferences of internal decision makers mediate the attributes of adoption decisions in organisations.

According to this reading of the literature, we decided to interview a purposive sample of key internal decision makers within real organisations to understand the potential of digital technologies to overcome identified causes for delay (see manuscript section 3). The decision-makers were selected based upon their familiarity with commercial real estate transactions and an accompanying high knowledge of the technologies in question. A second purposive sample of start-ups were identified as offering a unique, technology driven approach to any previously identified barriers.

The exact sample was not specified at the outset of research, nor was the sample size. Instead, sampling took a cumulative approach with data collected up to the point of theoretical saturation, when it was apparent that similar themes were being raised (Baker \& Edwards, 2012). This point was to be identified when new data collected began to confirm any developing theories identified and clear comparisons could be drawn between the perceptions of professionals and start-ups. Table S2 lists the (anonymised) sample of experts we have interviewed. All interviews were conducted between September and December 2018.

\subsection{Interview guide}

The choice of informal, semi-structured interviews involving open ended questions was selected as the qualitative data collection method. This method allows for the analysis of unstructured, raw data and is better suited to the understanding of phenomena and formation of theories than data collected through structured interviews or closed questionnaires (Denscombe, 2010: 111).

Semi-structured interviews were chosen over entirely unstructured interviews as preliminary research provided a broad initial list of questions to be addressed. In the following, we list the question catalogues that guided the interviews with (a) real estate professionals and (b) PropTech representatives.

\section{$\underline{\text { Real Estate professional question guide }}$}

1. What is your company's strategy towards tech adoption?
(a) procurement
(b) Accelerators
(c) In house funding

\footnotetext{
${ }^{2}$ https://github.com/Braesemann/RETransactions
} 


\begin{tabular}{|c|c|c|c|}
\hline Industry & Business model & Position in Firm & Method \\
\hline \multirow{5}{*}{ 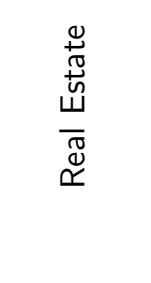 } & Investment Manager & Innovation Strategist & Phone call \\
\hline & Landlord & Digital Director and IT Director & Conference call \\
\hline & Legal Practice & Council & Face to face \\
\hline & Innovation Consultancy & CEO & Phone call \\
\hline & Intelligence / News & VP and Head of Automation & Face to face \\
\hline \multirow{5}{*}{ 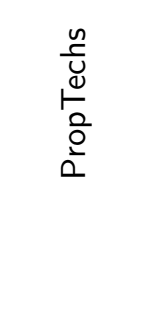 } & Blockchain Property Passport & CEO and Software Engineer & Face to face \\
\hline & Automated Valuation Model & CEO & Face to face \\
\hline & Online Property Passport & CEO & Face to face \\
\hline & Automated Valuation Model & CEO & Face to face \\
\hline & Residential Smart Contracts & $\begin{array}{l}\text { VP of Corporate Development and } \\
\text { Chief Software Engineer }\end{array}$ & Conference call \\
\hline
\end{tabular}

Tab. S2. Interviewed Real Estate and PropTech professionals

(d) Outsourcing

2. How do you view/rank the following technologies (from useless to highly relevant)?
(a) Blockchain
(b) AVMs
(c) AI data extraction
(d) Data rooms/e-conveyancing/data aggregation and sharing technologies
(e) Property passports

3. What needs to happen before each of these technologies will form a part of your business strategy?

4. How do you plan to overcome specific procedural barriers identified?

5. How do you plan to overcome specific social barriers identified?

6. How will you facilitate any needs identified during tech company interviews?

7. Do you feel you will benefit from increased transparency and liquidity?

8. Who is set to gain from a more liquid, transparent market, and who is set to lose (loss of fees/jobs etc)?

9. Would you consider releasing your transaction/property data into an openly accessible digital platform?

10. Would you consider selling/trading your information held on an individual property?

11. Would you consider making additional payments as part of an industry consortium to help local governments digitalise their search data?

\section{PropTech question guide}

1. What problem is your platform specifically trying to resolve?

2. How does your platform work?

3. At what stage of development is your platform?

4. How are you funded?

5. How much interest/help has there been from tech industry/real estate industry alike?

6. How much competition do you have?

7. What opposition have you met?

8. What are the pre-requisites needed for your platform to 'disrupt' existing processes?

9. What opposition have you met to your platform?

10. What procedural barriers do you feel your platform needs to overcome? 
11. Do you have any data/claims around you conveyancing process efficiency gains?

12. What is needed from the real estate industry to enable adoption of your platform?

13. What social barriers do you perceive around use of your platform?

14. Which other tech advancement compliment/facilitate your platform?

15. Do you concern yourself with the integration/standardisation of data formats across platforms used by different parties in a transaction?

16. How do you plan to overcome specific procedural/legal/social barriers identified below?

- A lack of digital process at land registries

- The need for a critical mass of users before system benefits are felt

- The financial and temporal costs of transition in both employee training and duplicating processes to the conveyancing industry

- A change in the ownership laws to force transference of any landlord held property data/ a system for sellers to warrant the information they provide about a property

- The need for new regulation to recognise e-signatures and smart contracts

\subsection{Data}

Data to be analysed took the form of word processed copies of handwritten interview notes produced by the researcher. This digital data, detailing the interview sentiments extracted, were sent to interviewees for validation, while offering a chance to comment upon its credulity, thus enhancing the quality of data to be analysed (Denscombe, 2010: 299). As objectivity is difficult to achieve under a purposive sampling approach, heavily involving the researcher's 'self' (Denscombe, 2010: 302) in the sampling process, all data has been made available for audit from external researchers, in section 3 and 4 of this document.

\subsection{Analysis}

Analysis of word processed digital data were then uploaded into qualitative analysis computer programme NVIVO, enabling a more in depth scrutiny of the data beyond that possible through classical, analogue techniques (Kvale and Brinkmann, 2009: 198). This programme enables coding to take a datadriven, content analysis approach. This allows data to be condensed into macro-themes (Denscombe, 2010: 281; Kvale and Brinkmann, 2009: 205). These emergent macro-themes were then compared across samples, with any clear similarities or differences between the views of real estate professionals and start-ups taken as significant.

\section{Interviews with real estate professionals}

\subsection{Innovation Strategist (M), large London based real estate firm}

As an innovation strategist, the interviewees role is to help identify change in the real estate industry and devise an approach that will put his organisation in a position to capitalise on any emerging trends. As a result, he is hugely knowledgeable about all things PropTech at both start-up level, meeting with start-ups on a daily basis, and from an industry overview, guiding his firm towards a successful future through identifying what is likely to happen over the coming decade.

Our interview started with a discussion over his firm's strategy towards innovation and it soon became apparent that this was not a company waiting, rather, one aiming to affect the change happening around them. Personal feelings towards innovation were that it was not going to 'disrupt', however change the weighting they gave to certain operations within the real estate value chain, adding that he felt intermediaries such as property managers would be those most likely to have their roles disrupted and therefore most likely to withstand technological adoption. The level of automation required to truly disrupt their business model as an investment manager was not imminent enough to raise any concerns. 
In the near term, he saw the rise of Auto Valuation Models as a big instrument in commercial real estate, enabling the accurate and immediate issuance of Indemnity insurance. There was not a feeling that these models would likely change the way the market operates, however bring efficiency to intermediaries in the transaction process noting how value and price are two very different concepts. We continued on to how his firm has partnered with numerous $R \& D$ departments spawned out of universities and industry networks, with an eye predominantly on 'big data' and how this can create new models of assessing real estate performance. Why can't mobile phone location data be harnessed to identify footfall as a partial proxy for user experience, and should this be factored into the way in which we valuate real estate?

When pushed to answer whether his firm would be happy to release data as part of an industry wide move towards creating a more transparent and liquid market, he was very well thought out in his response. Only if there was more to gain than purely introducing market liquidity. Without the regulation of public markets in which all information on trades has to be published by law, open real estate data does not seem to carry with it any benefit in kind to corporations as of yet. He felt that technology will bring liquidity and transparency and slowly bridge this gap between the public markets of securities and the private markets of real estate trades, completely changing the nature of real estate as an asset class. However, until this day came, he felt that there was no reason for an individual firm's real estate data to be made generally available.

A more tantalising proposal would be an industry consortium whereby data was anonymously provided to refine machine learning models for the mutual benefit of improved insights for all who subscribe. A potential use case for a permissioned blockchain to house the data exported from the machine learning programmes. He was also quick to point out that this single pool of trusted real estate information need not be run on blockchain mechanisms, only that it could be stored and accessed through one if, as claimed, the technology offers increased security. The technology behind the mechanisms for aggregating this data he felt already exist.

An Application Programme Interface, or API, is 'a set of functions and procedures that allow the creation of applications which access the features or data of an operating system, application, or other service'. Simply likened to one half of a bridge these links can be built into software platforms which enable others to be able to export the data they produce for use in their own technology. The Innovation Strategist felt that as opposed to looking towards new technology to create a trusted real estate information database, upgrades in old, currently difficult to integrate API's would present the ability for a platform to emerge able to house all the necessary information needed to eliminate transaction delays identified in section 3 of the research article.

At this stage of the conversation certain barriers to adoption became apparent to the interviewee as he was describing the advantages of such a platform. Cyber security seemed a key concern as did how to generate the social acceptance needed for users to input and allow access to their private property information. The nature of system inertia creating a high social cost of a transition would mean that any new system's performance would have to not only surpass the old, but improve efficiency to a level that these unaccountable costs are deemed worthwhile. The question behind who would bear the cost of any upgrade/system transition towards one of open API protocols bought us nicely onto the idea of an industry consortium to fund a mutually beneficial Research and Development department.

Taking lessons from world leaders in RD such as the Ministry of Defence, Google and Amazon all holding a huge market capitalisation and therefore able to steer the development of necessary advancements, the idea that the low market capitalisation of any single real estate company could be hindering industry technological progress was put forward. The researcher raised the idea that an industry consortium could lead to an accelerated rate of technological advancement. The interviewee believed that this would not be the case due to the heterogenous and fragmented market that global real estate is confronted with.

His concern, once again, was where would this money come from? The need for returns on investment 
within a specific horizon would not enable most companies to participate in such philanthropy. While his firm manage large sums of money, they themselves do not have such a luxury to endow. He felt that the best way for research and development to thrive within the real estate industry was through continued informal discussion and networks. He later drew our attention to Fifth Wall, a US real estate technology venture capitalist firm, who recently raised $\$ 400 \mathrm{~m}$ from 30 industry partners, as the closest example of this sort of consortium existing. Their investment decisions would be viewed as big indicators as to future market trends by the research division at his organisation.

Answering what he felt is currently needed within the industry to harbour the change he predicts is inevitable, the interviewee pointed towards the misaligned incentive structure throughout the real estate value chain. The main barrier to technological adoption, he felt, was due to the differing motives of actors within a real estate transaction. "It all depends on what you are paid to do" he stated before offering his insights on how there is not a belief that value created through technological adoption will accurately compensate those who are most deserving.

Within commercial property, there was no structure through which an increased user experience at the client facing level would be attributed and remunerated following an increased return on investment for the shareholders. The low velocity of trade coupled with the difficulties in aligning financial incentives of all intermediaries within a property transaction is not conducive to a culture of innovation. If the denominator through which the industry measured the quality of a real estate asset were to change from financially based indicators to ones that could incorporate additional social factors, such as footfall and occupant wellbeing, He felt that this mis-alignment of incentives would narrow and the adoption of technology encouraged.

\subsection{Digital Director (M) and IT Director (M), large London landlord}

The Digital Director stated that the biggest barrier to any real estate technology was the people. Having worked across multiple organisations, he outlined his feelings regarding a lack of individual technical literacy in real estate businesses. The IT Director widened the lens to incorporate the lack of a tech savvy industry with no clear model, or heuristic approach, within real estate for how to successfully invest in technology. The nature of flux within the current PropTech market coupled with the length of the conveyancing process, which currently spans multiple organisations, led the IT Director to the belief that such a model would not present itself anytime soon.

Their firms current tech strategy revolved around three key principles. Their main focus was first to digitise their current value chain, incorporating digital technology into existing manual processes to bring immediate efficiency gains. Secondly, their medium term goal was to anticipate the change happening around them to position their business accordingly to remain competitive throughout what they feel would be a period of discovery for the industry. Their third and final goal was to develop their own capabilities in order to capitalise on the opportunities once various technologies embedded themselves within industry norms. Their mixed method approach to doing so involved procurement as well as in house development. Through making relatively small investments into numerous technologies they have taken a "blue sky approach" of trial and error towards technological adoption, continuing to explore those which yielded the best initial results. At any point the characteristics desirable within any piece of real estate could change, and a flexible and agile approach would keep all bases covered. With the lifetime of an asset spanning many decades, who could have foreseen the current capabilities of a smart phone, not 20 years after the commercialisation of the first mobile telephones?

The idea of a collaborative industry attempt to generate mutually beneficial technologies did not seem to be a realistic solution to the problem of a lack of a heuristic approach. While the feeling was that individual firms had an enormous willingness to verbally collaborate, sharing ideas and learning from each other's mistakes, the reality was that very little meaningful innovation would result. This, the 
Digital Director felt, was down to the usual commercial profit motive. With too many factors influencing a commercial transaction for software to successfully standardise a process, the human art of 'making a deal' was the most cost-efficient way that this gain could be achieved.

Talking of disruptive technologies and potential disintermediation, the IT Director suggested that currently the biggest change was not occurring in the 'low hanging fruit', meaning the processes easiest to automate, as is being repeatedly touted within the industry media, but instead the "weak hanging fruit', meaning those processes which are not core to real estate operations. He felt that technologies which automate tasks currently outsourced by major companies presented both an easier investment decision as well as a lack of industry pushback.

Drawing on our hypothesis that an openly accessible, single pool of up to date, standardised property information would render many of the conveyancing process inefficiencies obsolete, the IT Director pointed us towards the established investment data analysis company VTS, currently operating with what they believed would produce a successful business model for any real estate data aggregation start-up. The Digital Director surmised the 4 key areas behind VTS' success as: an easy to use platform, highly incentivised contributors, commercially driven outputs and multiple access points for information collection. This data aggregation, the IT Director believed, was most achievable through a clever policy of recruiting well connected individuals who will bring with them a large network of personal contacts (aka data points). Questions of whether this model would be applicable for more specific conveyancing data aggregation companies came down to two factors: what data could be obtained and how best could it be monetised? The Digital Director was adamant that, due to the highly sensitive information contained within an individual firm's valuation of any commercial property, this would be the most difficult to obtain, while lease management, solicitor's due diligence and land registry procedures were already ripe for automation.

A more obvious point was raised that any technology would only be adopted if the cost of its development and implementation was less than the that of the tasks it is set to alter or replace. It was felt that currently this trade-off did not make the adoption of many technologies financially viable. While they may bring efficiency in terms of reduced time, at present they also increase the cost for a similar quality of outcome. One simple solution would be to increase technology education and training initiatives for individuals within their corporation. Currently, the belief was that digital literacy was not a part of the real estate recruitment process, while industry wide, focus has always been firmly on outperforming competitors as opposed to looking toward other industries for guidance. When asked whether those who would be using any new technologies were consulted before a product's development or during its subsequent trial, the Digital Director revealed that speculative trailing of new products and investment in uncertain technologies was alien to the property industry. The real estate industry will only invest in technology once it is confronted with a large enough problem to solve.

\subsection{Council $(F)$, large London legal practice}

Having been a part of our mapping process, Mrs Stone began by discussing the difficulties in technologies attempting to digitalise the search procedure through data scraping third party websites and amalgamating their findings onto a single platform. Besides the more obvious issues of a lack of transparency over the sources of data, the main problem here is one of liability. While start-up companies claim that they are facing industry pushback to their platforms, which they believe will render the outsourcing of the search due diligence process by conveyancers to companies such as Search Acumen obsolete, Stone felt this was a very naïve view of what is a complex contractual arrangement, with many specific terms and conditions, backed by specialist insurance.

If they, acting on behalf of the seller, were to engage a digitalised search platform, the information provided would not be legally warranted in a way that a buyer could rely upon as if the same information 
had been returned via a legally watertight traditional search company. Stone went on to produce a diagram outlining all the legal steps in place to ensure every party in a transaction would be protected in the event of misleading information. She was adamant that these processes cannot simply be bypassed with technology alone. When we suggested that any such system built on blockchain may present a way to warrant this information so that all parties can rely on its authenticity, she believed that the problem was not with the underlying technology used to gather the data, however the quality of the sources of data themselves.

Discussing HMLR's recent partnership with software company Methods, to experiment utilising the Corda Blockchain as part of their land title registration process, Stone once again dismissed the need for new technology. The Land Registry are good at producing information, she divulged, their online portal is simple and easy to use, while only a complex title causes applications to carry a delay. A recent training video being released to the conveyancing industry regarding requisitions will help to cut some of the delays in registration caused by the fault of solicitors.

We were keen to know whether she was aware of the conveyancing process behind the iBuyer business model, to which she was not, only stating that any conveyance would, by law, have to be represented by two separate solicitor firms despite the iBuyer companies acting as both the buyer's agent and the seller's agent.

Continuing down this need for new technologies to follow current regulation, Stone believed that any new conveyancing solution cannot attempt to bypass current law, instead has to follow suit for any hope of success. The Propy model of doing just this raised the question whether any eventual move towards fully automated transactions through the use of smart contracts could actually work. Putting words into

Stone's mouth, we suggested that smart contracts oversimplified what we identified as over 150 actions required for a full commercial conveyance. She believed that smart contract transactions were not wholly doomed but that they would require a property with clear searches and a clear title, a 'one page title', which is very rare in the common era. The legislation surrounding the construction of a lease is currently poor and as a result makes the process very difficult and property specific.

In residential conveyancing, the existence of a property chain means that one default purchase, for example on grounds of unwanted discoveries late in proceedings, can create a domino effect which results in a whole string of transactions falling through. The simultaneous completion of deals within a property chain is currently impossible for many factors, including yet un-automatable human preferences over moving dates. Technologies as such Propy's, which will rely on smart contract executions to trigger these moving events could find themselves with a tougher task than originally perceived when faced with the very real issue of a long chain of property transactions. Stone felt that the person who manages to solve this synchronicity issue would become very rich.

\subsection{CEO (M), Real Estate Innovation Consultancy}

We began with discussing the way he believed the valuation process would change in the future, and how this change would underpin a whole culture shift within the real estate industry.

For many years the fundamentals of valuation have not changed. Based on comparables from a very narrow sample, he said that historically this was the best the market could produce. Now the market is shifting towards large data sets, it's enabling a closer inspection of the factors generating value for each individual property. it is the way that will begin to deliver the best insights ... that is unless the client simply wants an official piece of paper for litigation purposes.

Real Estate is changing with technology one of the main drivers or enablers of this change. For an industry that has changed very little in the past, it can be very confusing as everything starts changing and it is useful to have a common banner under which all of this change can be pulled together. For him, 
this is the purpose of 'PropTech' it is nothing more than a hashtag to be used to reflect the technology driven change in property. However, for now, it plays a really important role in getting traction.

The sector has got a long way to go and in truth is unlikely to ever get to the point of stability that it aims for as the impact of technology will continue to grow and change, however the majority of people in property in his experience 5 years ago, thought technology was pretty inconsequential, beyond a basic tool to use. 2 years ago, they were intrigued and the 'PropTech' banner was a useful way of getting people on board with the idea that technology may have a wider impact on the market. Now, the majority of people get that something is going to happen, but now want to know what to do, more depth. PropTech is still a useful vehicle to help the market with this change, but needs to move from 'did you know technology is going to change things' to 'this is how it will change things and this is what you can do about it'.

He does not think the term PropTech has been overused, however as it has become more popular has inevitably been used by different parties with a different understanding of what it is or a different agenda.

For completeness, his view is that 'PropTech' is a hashtag that reflects the coming together of 'property' and 'technology' and the change that that drives. It is not so much about the technology itself, but much more about business models and culture. Start-ups are a major part of this change as they were not viable businesses just a few years ago, but so too are major built environment tech companies, real estate advisors, occupiers, investors, major tech companies, Government, etc all of who need to (and are starting to) transform the real estate sector.

His description of the legacy systems in place in current successful real estate organisations drew parallels with Christensen's seminal 1995 report into the evolution of the hard drive industry in which he coined the term 'disruptive technology'. In both instances the incumbents adopted the stance that if the current business model is still lucrative and our current clients are satisfied then why change? He feels this outlook is so embedded into the nature of the industry that change will only occur under two scenarios: 1) regulation enforces change, or 2) there is a tangible benefit for companies, normally this would be reflected though value, so the way we derive real estate value changes.

Happy, inspiring environments will begin to fetch a premium in the market due to the increased productivity generated. The problem becomes how to capture and measure such intangible characteristics while the current valuation method hinges on location and size comparables? A similar issue emerges when we consider the sustainability aspects of a building. While greener buildings are being mandated and also desired, we have yet to capture the health benefits to occupiers and wider society within valuations, so they reflect the true value that an asset offers. To a degree, this has not mattered so much in the past due to the length of leases, but it will become more important as leases get shorter.

The answer to this problem of measurement lies with data. The more flexibility individual real estate valuations have around the data they incorporate, the more transparency over the drivers behind the true value of a piece of any asset will emerge. The increased transparency into the drivers of real estate value will create liquidity, facilitating increasingly more data to be collected and factored into the changing model of valuations. True, although there is a bit of a paradox here that as more and more complex technology is used for a valuation, it can become less and less understandable - so potentially less transparent.

The underlying message is that whether legacy organisations accept it or not, the current model through which we value real estate will change and with it the data flows and financial models required.

Discussing how the underlying processes for a successful transaction to occur may change with recent advances in technology, he again took a broad view to incorporate all transformation happening within the industry. He identified 2 rules which are applicable regardless of which practise you are inspecting:

The first is that the real estate processes historically seldom changed. Technologies thus far have only managed to streamline stages within existing processes, but not negate them all together. This increase 
in efficiency is something he predicts will occur once again, and not a total disruption or disintermediation at the hands of new technologies. He cites the tasks of data collection required for valuations and local authority searches required for conveyancing as two areas theoretically ripe for automation, before noting that in reality there are many constraints which could prevent this from occurring. The second was that the drivers behind how we are using real estate are changing and with it, new complexities behind the data on which the industry will operate.

Blockchain, with its touted capacity to completely revolutionise the conveyancing process, is a technology that has been way overstated in his opinion. While carrying belief that it will play a large role in the future of real estate, he questions whether many current products applying the technology as a substitute for a database are just doing so to raise profile. In the UK there is already a trusted central authority in HMLR and there is little need to decentralise or distributivity store the data currently in their possession. A better use case would be in the global south economies where no trusted or official land registry exist. Blockchain may well be, or at last be part of a solution, but it comes with down sides and the benefits need to match the problems for it to be applied successfully.

The "PropTech" psalm resonates: "We tend to overestimate the effect of technology in the short run and underestimate the effect in the long run".

The legacy of data held by organisations such as HMLR is the UKs greatest strength but also brings with it challenges. If 'data is the new oil' then we are sitting on unrivalled pools, however what use is oil when we have yet to create the drills to extract it with? Machine learning technology is one potential 'drill' speeding up the process of data extraction, but this process can be slow and the days when we are able to benefit fully from the enhanced insights it will provide are still far off. This process takes time, money, political change and political will, 4 things that are difficult in the current climate. With location data underpinning the whole real estate market, that currently held in the hands of conveyancers should also be accessible to the wider market.

After discussing the challenges in registry legislation and financial regulation required for any tokenisation of real estate ownership, he closes with an overview of the current ecosystem of UK start-ups commenting that some offer great technology solutions that simply cannot work in the real world. For example, some completely ignore the legal and public sector influence in the house buying process.

\subsection{Vice President (M) and Head of Automation (M), intelligence / news firm}

The Vice President believed that the standardisation of lease construction was highly possible. His success launching previous software, which did just that, has led him to the view that the biggest barrier to the adoption of automated contract software was the lawyers themselves. His software would produce a standard template that could be altered based on a series of questions and answers input by conveyancers themselves thus speeding up the process all together. He felt that their platform only became accepted by the legal community once the fee structure transferred from hourly rates to a fixed fee, motivating conveyancers to complete deals faster.

The Head of Automation believed the same, commenting that both the lease creation and reviewing periods could easily be standardised, enabling any changes in lease information from this standard format to be captured in a data driven way. The main barrier he perceived for a lack of adoption in new software, such as their own, is the lack of an end to end solution for the full transaction workflow.

Discussing the accuracy of lease extraction technologies digitalising existing documentation, the Vice President felt that the key determinant of success would be when they become accurate enough to satisfy lawyers professional indemnity insurance requirements, which currently they do not.

There were many barriers to a full end to end transaction workflow platform, both operationally and regulatory, identified by the Head of Automation: 
- The primary change needs to occur with the data structure of leases which at present has no standard format or wording.

- A secondary issue is with the reliance on 'wet ink' signatures and the regulatory and social changes needed in order to enable the consistent use of e-signatures.

- Blockchain itself would require new mechanisms of proof of work in order to successfully scale. A system on which smart contracts executed real estate title transfer currently is unfeasible due to the constraints of high energy consumption and validation time required by existing Blockchains.

- The security threat of an attack or natural disaster located at one of the data centres was of little concern to the integrity of the Blockchain systems, with the Head of Automation correcting our assumption, stating that it would require simultaneous attacks on multiple data centres to disrupt a large decentralised network.

The Vice President directed us towards PISES which recently became OSCRE, (http://www .oscre. org) a body driving open standards for real estate data, recommending us to research why they have failed to achieve this as a good avenue for further research.

Both experts felt that that the legacy systems in place within the legal community and the lack of digital natives present a large barrier to technological adoption.

While Amazon are likely to enter the smart buildings/construction realms of real estate, the thought that Google, Microsoft or Facebook were likely to enter the software provision market of Prop/Law Tech was unlikely due to the lack of financial incentives to do so.

Fundamentally data needs to change: common data requirements and terminology need to relate to specific clauses in leases so that information extraction can be readily facilitated. This will be further enabled with the acceptance of e-signatures, allowing digitalised data to remain so throughout the workflow.

\section{Interviews with PropTech executives}

\subsection{CEO (M) and Software Engineer (F), Blockchain-based Property Passports}

This company is a start-up attempting to create a property passport, focusing more on the physical condition of a residential property than the legislation required for its trade. Their suggested proof of concept is to create an electronic logbook for Property Managers to securely upload the necessary information regarding each of the parcels they oversee. This would include specifications of fittings, warranties and user manuals, meter readings, details of any safety checks and maintenance works to give a real time overview of the condition of any properties. While in the very early stages of development, their Blockchain-based idea would certainly be revolutionary in the world of residential real estate, helping to eliminate due diligence inefficiencies associated with defect disclosure, surveys and valuations at the point of transaction or mortgage application. The owner would be motivated to keep information up to date as it would act as a signalling effect to the market, perhaps increasing (or avoiding a reduction of) the property value.

During our interview it was clear that this seemingly highly desirable concept would, in reality, face many barriers both procedurally and socially.

The main barrier seemed to be the format in which data would need to be stored. In order to have a digital file of specifications, warranties, instructions and maintenance works within a property, the information would have to at least be provided in a digitised format, and ideally fully digitalised. The way receipts, invoices and reports are currently handled in residential real estate are still predominantly analogue, and as with the implementation of any new system, there are many factors as to why this will 
be difficult to change. We have already highlighted the issues of data sharing between differing companies, using differing processes, held in differing formats, while the motivation behind keeping the existing mixed formats span avoid numerous social and financial costs to be incurred by firms and individuals alike. Such problems include duplication of processes through a lack of critical mass or software integration, costs of retraining the professional community and the time associated with locating and digitising historical information.

Owners would only be motivated to upload information which would positively effect property price and avoid any negative findings. Due to caveat emptor, this would still require a full survey to be undertaken by the new purchaser. The extent of deterioration of old parts cannot be relied upon through a historical instalment date, as their use will determine the amount of their depreciation in value, while new installations are not necessarily less prone to future fault.

A third issue would be how to enforce transference of this information along with a sale. Previous studies indicate that legislating the disclosure of information held by the landlord does have positive price effects, but also negative legal consequences surrounding any genuinely unknown, omitted information. A solution involving a decentralised storage of all property information with individual access and information uploading rights granted alongside ownership title would be a good use case for blockchain technology. However, risks would surface surrounding the integrity of the organisation holding the right to grant or deny this access, cyber security and personal data protection.

Any property passport platform that wanted to speed up the transaction process through housing all individual property search information in one single location would need to open a dialogue with the necessary local authorities, who would then have to be willing to co-operate. Such co-operation with a private company is unlikely to happen due to the underfunding of these public departments, and difficulties in time and effort of data standardisation.

There was also a feeling that the industry was under-prepared for the introduction of new concepts and ideas. That any 'disruptive' change in the system by which we trade property would require a more welcoming approach that could be lobbied by consortiums such as the Law Society. While claims around Blockchain are being pushed from the start-up community, the industry is yet to adopt the same optimistic approach.

\subsection{CEO (M), Automated Valuation Model}

This company is attempting to create a single database of accessible information regarding all properties. Their proof of concept however relies on the use of an Interactive Automated Valuation Model though a smart phone app. They collect user sourced property data through a series of simple and quick questions upon initial login. With this data they offer the user recommendations on the best service providers for the property, with an easy and simple switch service, as well as a live, easy to understand graphic of their current, fair property price. This property valuation feature can be opened further to find financial statistics such as what yield you have currently achieved on initial purchase price, the rent you could expect if leased and how much could be borrowed against any property. This AVM, claimed to be at $87 \%$ accuracy in the UK market, will become more accurate the more users they gain and the more property information each user incrementally adds through interacting with various features upon the app. Initially making their revenue from referral fees off partnered service providers, once critical mass is gained, their platform is designed to easily expand to incorporate open banking and legislative file uploading features which will enable transaction services, mortgage offers, partial investment opportunities and potentially a commercial real estate application. If successful, this will help to increase speeds and reduce costs associated with many of the current transaction bottlenecks identified.

Motivating users to upload relevant information which could speed the transaction process will be less of an issue with their platform than with a stand-alone property passport. Their offer of friction-less 
service provision to the end user seems an innovative way to crowd source much the necessary information required for a transaction, while not revealing that motive up-front based on the understanding that such an application can only be achieved upon reaching a critical mass of users. However, this is not to say that their goal to create a ubiquitous real estate platform does not have its barriers.

While users are motivated to input the correct data about their property, there is still a large element of trust in unverified data and information stored in third party organisations to perform necessary cross checks. While not mentioned in the interview, data manipulation could play a large role in the functioning of the app and the business, if opportunities for a user's personal gain through inputting misinformation were identified. This would lead onto questions of cyber-security, if all information regarding to an individual's finances and real estate holdings were to be stored in a single location, but with banking and trading apps already thriving, then this trust should not be too difficult to gain.

Questions were raised of the AVM's inability to model human sentiment and preference. His simple solution was that it was not going to follower the iBuyer model of an instant offer, buy-flip-sell strategy, and any price was merely an indication of fair market value. Their eventual sales feature would still require negotiation and acceptance of an offer from the owner. However, with more information provided upfront, there should be less room for debate, still speeding up this stage than if transacting through conventional methods.

The sticking point of this technology once again comes in the format which data is held, required for any eventual branch into the digitalisation of the conveyancing process. Their legislative file uploading feature will only mirror a data room for uploading digitised documents and does not possess any unique features over the data rooms currently in operation. While this is useful for any future transaction, it still relies heavily on a critical mass of users adopting the platform to avoid difficulties of software integration. As opposed to the well thought out motivating factors leading a user to upload their property characteristics, the platform does not seem to offer advantages to the owner for uploading any legislative documentation. It also does not begin to address the problems surrounding ownership of this information and how to guarantee its transfer to any future purchaser.

Their reliance on critical mass is heavily dependent upon social adoption. Their marketing towards millennials through choosing to operate via a smartphone app is solely aimed at amassing users. Only then will any innovative transaction function based off their property database and AVM technology be developed. Issues of requisitions at the land registry will still exist, while problems surrounding up to date searches will require local authority co-operation.

The most intriguing topic of our conversation was what was not said: Blockchain. While they were not against integrating a better, more secure operating system, at no point did they believe their concept depended upon the success of Blockchain technology, instead relying on already proven Artificial Intelligence techniques and existing software protocols. Their proposition represents less of a technological disruption and more of a business innovation.

With the present aim of the company to generate users, the need for regulatory recognition of potential future norms, such as e-signature and smart contracts, were of little concern to the CEO. He believed that once change came, regulation would be forced to recognise any new system, as opposed to stifling innovation through pre-empting regulatory reform.

The following supplementary data comes from a follow up email exchange:

(Q) How would an AVM include development potential of land?

(A) We are not very focused on this at the moment, but it would be interesting to do. Right now we have $30 \mathrm{M}$ existing UK properties plugged in and I guess over time, as new properties are built and added to the database, the same machine learning would apply to calculate all these things. It would be 
a 'development' feature to calculate potential build financials that could be added. Essentially you are trying to value 20 properties now? Plus land value? Considering rental potential, costs etc., this can all be done but for us. At the time being, we are focused on the existing stock of $28 \mathrm{M}+$ properties and getting UK homeowners to track their home with us.

\subsection{CEO (F), Online Property Passports}

The firms pilot products, which are soon to be trialled, use existing API technology to plug into the UK Land Registry's data and offer a predicted conveyancing timeline for individual residential properties. Their technology, designed in conjunction with a leading UK university, will spawn three products aimed at estate agents, buyers and sellers, offering each more transparency into the legislative side of a real estate transaction. Their website details how through "checking 54 points on the title deeds, Property Passport predicts your completion timescales and provides you with your bespoke Property Passport to make it happen quicker - on average completing in less than half the national average".

This initial incremental step towards a full AI based conveyancing platform is aimed at front loading all the information about a property to better inform early decisions, while reducing fraud and unwanted discoveries late in the transaction process. Specifically, these discoveries include information such as any notices on the title which could lead to a rejected registration or requisition and a confirmation of correct boundaries and registered address, often different from the known postal address. The number of times a transaction fails because of an issue that crops up during the conveyancing process is negligible. The number of times a transaction fails due (at least in part) to the delays in the post offer process is approximatelx $20 \%$ - a figure that their platform is aiming to reduce.

The CEO raised her frustrations with the outdated practises required by the current legal system in the UK as she called for a change in focus. Having studied law and establishing a career as a practising residential conveyancer, her expertise has been utilised by both the Law Society and a recent all parliamentary working group on the use of technology in legal services. She feels that conveyancing has become an exercise for the conveyancing industry and lost touch with the end consumer. Information required by law such the disclosure of any rights deriving from local community traditions; payments of a corn rent (rents paid in lieu of a tithe); franchise rights (such as the right to hold a fair) are only relevant in the smallest number of cases, while modern information such as the 'Airbnb' rental value of your home, any planning permission on neighbouring plots, or the size of any extension that could be added to any investment property, which she feels would be useful to know when making a purchase decision, is not considered at all.

A 2017 blog post she directed us towards writes: 'We need to move to a situation where data relating to properties is real time, accessible instantly, and most importantly, relevant and useful ... The disruption that the UK estate agency market really needs has to consider the whole of the transaction, including conveyancing. This is a model that we can see operating in other countries to good effect such as the United States where realtors must not only market a property, but also act for their clients in the legal transfer of title once a sale has been agreed. There is no need for a separate conveyancer in addition. But what has prevented the roll out of such a service to incumbent agents in the UK market is that conveyancing in the UK includes some reserved legal activities; indeed, realtors in the US require a license for the same reason.'

When asked why the UK conveyancing community had not looked towards technology to help frontload data and negate late defaults before, she believed that a fear of intermediation within the professional community was to blame. Reciting the well-rehearsed line that technology will not replace jobs, but increase efficiency, she walked us through how their product will automate many of the repetitive, time consuming and low value added tasks such as data inputting, thus allowing more time for conveyancers to focus on the complex tasks which require a legal expert to complete. 
The previously identified problem with conveyancing technologies of duplicate processes led us to question whether lawyers on both sides of a transaction would later have to check the validity of Property Passport's third-party generated legal information, thus in reality not altering the current process at all. She felt that while this may be the case during their pilot, subsequent use would bring about the realisation that the data their platform provides prior to any transaction was aligned with that which is currently returned from the Land Registry toward the final registration phase and often bringing with it untimely delays and unwanted discoveries. The final product would carry with it an insurance against any incorrect information provided, warranting added trust and acceptance.

Due to time constraints, the final question was bluntly directed towards what she felt were the biggest barriers for her technology within the real estate industry. Her replies were equally as concise, as she felt little need to expand upon her previous explanations as to the critical mass required for trust to be gained in their software and the shift needed within the culture of the industry towards more modern composition of the conveyancing process as opposed to the current use of technologies which she believed were simply digitising existing poor procedures.

\subsection{CEO (M), Auto Valuation Model}

This is start-up partnered with a leading UK University, whose platform would provide solutions to the delays identified in collating pre-sale information and replying to CPSE's. The information required for these processes, they believe, should not be stored in the filing cabinets of the solicitor's office, but with the plot of land to be transferred. Their database uses the unique property identifier used by the Land Registry and boundary line as provided by the Ordinance Survey, superimposed over the Google Maps visual system. This helps re-imagine any historical inconsistencies in human mapping error, allowing for a digitalised identifier of the boundaries (all be it very unofficially), potentially alleviating another identified bottleneck. For each plot of land to be traded, their API (a form of digital link) to the Land Registry database enables users to download the official title documents associated, helping inform better investment decisions prior to instructing a solicitor. The CEO was adamant that this lease data could only come from an official source as the key to a successful output for any system is the quality of the data input. As user numbers grow, and more information is downloaded, the data available within the platform becomes more comprehensive. This added to the user input data from their property management feature could eventually be used to inform a commercial property AVM. Their USP is the target audience they intend to capture.

The monopoly on data that real estate agents hold, fed into analyses firms like VTS and CoStar, is based around large transactions with prime locations. The price these analyses firms charge for their insights only makes them viable for the major investment organisations. The CEO believes that the real value lies in being able to offer a more holistic view of commercial property. Their platform will enable the same level of investment insight but for owners of small portfolios of commercial property within regional locations; effectively democratising the data away from the agents and into the hands of the landlords by offering access to their search platform for a small fee and any subsequent new lease downloads. This focus on the smaller commercial real estate players, will enable them to build a more accurate AVM for the commercial world. He comments: "while the industry will say this can not be done as no two London office buildings are the same, and the level of transactional data is not sufficient, what they do not realise is that large similarities can be drawn between the remaining majority of the market, with a higher frequency of trades".

This "naysaying" attitude, he believes, is also true of lease agreements. In the majority of cases there is no need to instruct a solicitor for a conveyance. As with residential property, $95 \%$ of lease clauses can be standardised as they are required for all transactions. The $5 \%$ of nuisances in any particular lease are those which would have been added. If lease information is digitalised, as on their platform, this can be 
easily identified through looking at the differences between each consecutive historical agreement. Once this information is uncovered, leases could easily be drawn up between landlord and tenant without the need of lawyers who do so to protect their roles. These leases could easily be electronically signed and recorded, citing the inefficiency of having to "re-digitalise a digitalised document", meaning the need to print off what is already digitalised file so that you have a paper document, sign it, scan it, send it back, and then rely on lease extraction software to digitalise the relevant data. While agents only make their fee on a successful transaction, high street lawyers are not incentivised to ensure a successful deal, only to make their expertise appear indispensable to the process, collecting repeated fees on second instruction of any failed transaction.

The belief that agents and solicitors have all the power over real estate data which should belong to the landlord drives much of the interviewee's feelings towards the real estate industry and where change is required. New technology he believes is not the answer, but ensuring open source, good quality data. The major injustice, he believes, is the fact that this data already exists, but the protectionist attitude with which the real estate industry currently guards it, enables them to charge a premium for their services to the landlords, who are the ones holding all the risk and to who the data should rightfully belong. The current practise of agents to return favours within their personal network, he likened to 'insider trading', this creates an obligation within the market to other agents, and not to the client. In the same way that the stock market has transitioned from 'wolf of wall street' to data science, as to will real estate. The fear of failure within the industry spurred on by the large downside risk of a bad deal has generated a closed-door culture, one not conducive to the trial and error ecosystems needed for innovation and reform.

\subsection{Head of Corporate Development (F) and Chief Software Engineer (M), Smart Contracts}

We were first directed towards a recent interview by founder of the International Blockchain in Real Estate Association, Ragnar Lifthrasir, in which he admitted that his company, Velox.RE, had come to the conclusion that "tokenising land titles" was the wrong way to go about using blockchain as a tool for land title transfer and recording.

Velox.RE's trial involved the exchange of a coloured coin, a form of nominally worthless cryptocurrency encoded with the digital ownership title of a real estate asset, in order to represent the changing hands of ownership from seller to buyer.

This was not what the interviewed company was doing or intended to do, with the Chief Software Engineer reaffirming our understanding: "We are not doing anything but recording the stages of the transaction". Leading us to ask why they have decided to use Blockchain merely as a record of individual stages of any transaction, and not for its smart contract capabilities in executing trades?

He felt the need to clarify our understanding of their business once again. We were unaware of the three separate, modular systems they had launched, not to be confused with one another for reasons of clarity. The first is their cryptocurrency based real estate listings platform. The next is their Blockchain based transaction recording system, which is a separate project form their Registry, which is being trialled as a means to record the final land title ownership documentation.

He then answered that their business model was based on the use of Blockchain and so they did not want to have to wait until each legal jurisdiction passed laws so that it was legally recognised a medium of land title transfer, as was Lifthrasir's stumbling block with the use of coloured coins. Instead, in order to gain first mover advantage, they decided to follow existing legal processes, using Blockchain only as a recording system to the progress of a transaction.

They would record any final transfer of ownership in their Registry only to demonstrate blockchains capabilities while officially logging the required documentation through existing registry protocols.

Their advanced capabilities over existing recoding systems lie in Blockchains security and ability for remote completion, justifying their use of the new technology. 
We used this opportunity to further enhance our understanding and asked a series of quick-fire questions involving concepts which we had yet to grasp. In almost all cases, the Chief Software Engineer could refer us back to their reasons for adopting a model, which simply follows and records existing protocols. While it was clear we had yet to grasp the simplicity of their transaction platform and kept confusing it with their registry.

Q1) What are the tax implications of your transactions?

A1) They have nothing to do with tax, although they could record this in the future while incorporating it in the fees charged upon purchase.

Q2) Can you create a Blockchain registry with the UK law of general boundaries?

A2) Conveyancers will do what is necessary in any legal jurisdiction they are in and we simply record what has been done.

Q3) How would a Blockchain registry respond I the event of inheritance/divorce proceedings?

A3) The same way that a normal registry would. The court decision would be final, and the legal rights would be given to the land registry who would simply record the new ownership in the Blockchain based system.

This would be a huge issue if the title itself was tokenised. Which in their model, it is not. Many are starting to see that tokenising title is not the way forward given the amount of regulatory issues involved.

Q4) What needs to happen before fully automated, smart contract based, instant purchases can occur?

A4) Their strategy is to have the conveyancers on board and to bring new efficiency to their workflow, not remove them. Their transaction tool would help them manage their data accordingly. However, if governments were to buy into the technology then perhaps legal title could be traded like stocks. This is both a technical and a political issue, whereby the existing land registry would have to be able to integrate with any Blockchain system, while also handing over the control of their data. Some markets may want better liquidity and price discovery and therefore attempt this as it would be possible to achieve within the current legal framework.

The existence of 'single day trades' would be risky for any investor. The nature of property as a physical asset means that change can easily happen over time which might not be reflected in the most recent documentation. The need for a property inspection negates this risk. A lien from a third party also presents a major risk to any instant trading.

The length of this process is mandated in some regions of the world purely for this reason of defect or dispute discovery.

It is something that would be able to be done, but it is not a good business model!

Q5) What would happen to the registry if they go bankrupt?

A5) That is the whole reason they are using Blockchain because it enables the land registration to become provider independent. The code is all published, and the Blockchain will exist independently of companies.

Q6) Would there be a need to retain the existing legal community to understand Blockchain?

A6) No, the user interface would appear much the same and any documentation presented for for legal purposes would be no different. 
Q7) Does this then rely on your system to be regulated so as to prove that your documents are legally admissible?

A7) In any jurisdiction there is only one valid and accepted land registry system anyway. It should not make a difference in court whether this is run on our Blockchain or any other software provider.

At current their registry documents are not admissible, and their hashes only legally represent "evidence that somebody has put something on the Blockchain", time and date stamped. That is not to say that their underlying system could not be used by an existing registry.

Q8) Who is liable in the event of a system failure/breech?

A8) That would depend on the contract, but the same would apply for the current software providers.

We finished by opening a discussion with the aim of establishing what they felt were the barriers to adoption for their platform.

The Chief Software Engineer thought that they had plenty of competition in this space from companies not using Blockchain, and that key to success was having a good business strategy: "If we can not convince real estate professionals to use our transaction recording tool, or governments to partner with us to develop a Blockchain land registry, then we are not very good salespeople. Some companies are already dominant in this crowded LMIS $^{3}$ provider market and the majority of people have not heard of us".

The drive for the adoption will come from the public. Voters in educated economies will want more democracy. The Blockchain offers a way to create land titles which are guaranteed to survive, overcoming war, natural disaster, political corruption and fraud. While industry collusion and government's relinquishing control will be difficult to overcome.

The Head of Corporate Development finished the conversation putting the focus on "trust". Comparing new systems of transacting real estate with the historic transition to online banking as a new system of transacting money. "It takes time, people need to understand where the benefits are".

\section{List of Start-ups working on specific technologies}

Applicable start-ups considered

During research, the authors estimate they spoke to upwards of 100 start-ups while attending numerous PropTech conferences at which hundreds more were exhibiting. All the while, keeping a log of emergent companies identified through the real estate media. The list of those referenced below does not constitute a recommendation, and is only supposed to be illustrative of some of the developments in technology directly applicable to this research. These developments were considered in the description of applicable technologies in section 4 of the manuscript.

\section{Automated Valuation Models and Instant Buyers}

CREID Automated Valuation Model for residential property using crowd sourced information through a real-time property tracker app. Still under development.

GeoPhy Use supervised machine learning to create automated valuations for commercial real estate. https://geophy.com

Hometrack Auto Valuation Model used by 12 of the UK's 15 leading mortgage lenders. https : //www.hometrack. com/uk/

\footnotetext{
${ }^{3} \mathrm{~A}$ logistics management information system (LMIS) is a system of records and reports - whether paper-based or electronic - used to aggregate, analyse, validate and display data (from all levels of the logistics system) that can be used to make logistics decisions and manage the supply chain.
} 
Nested AI powered iBuyer, providing instant offers for UK residential property.

https://nested.com

Offerpad AI powered iBuyer, providing offers for US residential property.

https://www . offerpad.com

Opendoor AI powered iBuyer, providing instant offers for US residential property.

https://www. opendoor.com

Proportunity AVM powered instant loan provider.

https://proportunity.co

Property Passport, IoT and Building Systems

Ask Porter Digital property management assistant which uses AI to arranging viewings and inspections, resolve issues and collect rent.

https://askporter.com

Chimni Residential property passport providing an online repository for all related digital documentation. Product still under development.

https://www.chimni.com

Demand Logic Smart building insights platform allowing for energy optimisation and predictive maintenance.

https : //www.demandlogic.co.uk

Disruptive Technologies IOT wireless micro-sensor developer able to detect temperature, movement and proximity.

https://www.disruptive-technologies.com

Property Made Liquid Blockchain based property passport developer.

http://www.propertyml.com

Homeowners Passport Predicts completion timescales and provides a bespoke property passport report to speed up residential conveyancing.

https://www.homeownerspassport.com

Faira Brokerage model combining a full buyer's pack with insurance to protect sellers against abortive transactions.

https ://www.faira.com

Blockchain Smart Contracts and transactions platforms

ChromaWay Blockchain developer and residential smart contract researchers who are pioneering trials in residential transactions.

https ://chromaway.com/cases/

Propy Blockchain-based brokerage and land registry powered by smart contracts.

https://propy.com/browse/

UcaDo An end-to-end rental and transactional platform for residential real estate.

https://ucado.co.uk 


\section{Lease Information Extraction and due diligence}

Architrave Commercial transaction and life cycle data room, similar to a commercial property passport concept.

https://www.architrave.de/en/

EVANA Data room which identifies the type and the content of documents by artificial intelligence relevant for a RE transaction.

https://www . evana.de

HighQ Legal data room claiming to streamline legal service delivery, operations and client engagement. https://highq.com/gb/

Kierra AI driven legal contract data extraction identification and analysis software. https://kirasystems.com

Leverton AI powered data extraction platform for legal documents. https://www.leverton.ai

Nimbus Maps Geo-location tagged property passport/data room for UK commercial buildings. https://www. nimbusmaps.co.uk

Orbital Witness Using spatial analytics and satellite imaging to automate legal risk profiling in real estate, providing an instant assessment of legal issues on land and property.

https://www. orbitalwitness . com

Openbox Robotic Process Automation for Real Estate due diligence. https://www . openboxsof tware.com

Proda AI-enabled software to automatically capture, standardise and quality check commercial rent roll data.

https://proda.ai

Search Acumen Digitalising the UK land searches process.

https://www. search-acumen.co.uk/Home

\section{References}

Baker, S. E., and Edwards, R. (2012). "How many qualitative interviews is enough?" Expert voices and early career reflections on sampling and cases in qualitative research. Southampton: National Centre for Research Methods.

Denscombe, M. (2010). "The Good Research Guide for small scale-social research projects". Fourth Edition. Open University Press. ISBN-13: 9780335241385.

Hoffmann, V. (2011). "Knowledge and Innovation Management". Module Reader. Hohenheim University.

Kvale, S. and Brinkmann, S. (2009). "Interviews: Learning the Craft of Qualitative Research Interviewing". Second Edition. Sage Publication.

Levison, T., Levison, D. (2019). "How to Adopt Technology in Commercial Real Estate". ComissionTrac Whitepaper. Available at: https://commissiontrac.com/embracing-technology-white-paper/

Straub, E. T. (2009). "Understanding Technology Adoption: Theory and Future Directions for Informal Learning". Review of Educational Research, 79(2), 625-649. https://doi.org/10.3102/0034654308325896

Vagnani, G., Volpe, L. (2017). "Innovation attributes and managers' decisions about the adoption of innovations in organizations: A meta-analytical review". International Journal of Innovation Studies, 1(2), 107-133. https://doi.org/ $10.1016 / j$. ij is. 2017.10.001 